\title{
Effect of Intravenous Immunoglobulin in Reducing Bilirubin Levels in Hemolytic Disease of Newborn
}

\author{
Shaimaa Waheed Ibrahim El Fekey*, Hamed Mohammed El-Sharkawy ${ }^{1}$, Aisha Abd-Ellatif \\ Elsaied Ahmed ${ }^{2}$, Mohammed Abd-Ellatif Nassar ${ }^{1}$ and Marwa Mohamed Elgendy ${ }^{1}$ \\ Departments of ${ }^{1}$ Pediatric Medicine and ${ }^{2}$ Clinical Pathology, Faculty of Medicine, Tanta \\ University, Egypt \\ *Corresponding author: Shaimaa Waheed Ibrahim El Fekey, Mobile: 01000994337; Email: \\ shaimaawaheed3@gmail.com
}

\begin{abstract}
Background: hemolytic disease of the newborn is an autoimmune haemolytic disease and caused by antibodies produced due to $\mathrm{Rh}$ and $\mathrm{ABO}$ incompatibilities. Neonatal jaundice is a common clinical problem encountered during the neonatal period. To avoid the associated neurological complications; exchange transfusion and phototherapy have been traditionally used. Aim of the work: was to assess the efficacy of intravenous immunoglobulins in neonates with $\mathrm{Rh}$ and/or $\mathrm{ABO}$ incompatibility in reducing the duration of phototherapy and the need for exchange transfusion and hospital stay. Subjects and Methods: in this clinical intervention study 40 patients diagnosed with hemolytic disease of newborn were grouped into group A and B. All neonates were treated with standard protocol for phototherapy and exchange transfusion. Group A patients received only phototherapy. Group B patients received intravenous immunoglobulins in a dose of $0.5 \mathrm{gm} / \mathrm{kg}$ of body weight single dose and phototherapy. Exchange transfusion was given to the patients of both groups if the bilirubin rose by $0.5 \mathrm{mg} / \mathrm{dl}$ per hour. Results: there was significant decrease of bilirubin level in group B [that received phototherapy plus Intravenous Immunoglobulin (IVIG)] than group A [that received phototherapy only]. Hospital stay and duration of phototherapy decreased in group B than group A. Number of cases exchanged blood in group A was higher than cases of group B. Conclusion: addition of intravenous immunoglobulins for treatment of hemolytic disease of newborn significantly reduces bilirubin levels, duration of phototherapy, need for exchange transfusion and hospital stay.
\end{abstract}

Key words: Hemolytic Disease of Newborn, Bilirubin, Intravenous Immunoglobulin.

\section{Introduction}

Hemolytic disease of the newborn is an autoimmune haemolytic disease and occurs as a result of hemolysis and shortening of the life span of the newborn's erythrocytes because of antibodies crossing from the mother by the placenta. Hemolysis of erythrocytes in the fetus and newborn is most frequently caused by antibodies produced due to $\mathrm{Rh}$ and $\mathrm{ABO}$ incompatibilities (1). Exchange transfusion and phototherapy have traditionally been used to treat jaundice and avoid the associated neurological complications. Because of the risks and burdens of exchange transfusion, intravenous immunoglobulin (IVIG) has been suggested as an alternative therapy for alloimmune hemolytic disease of the newborn (HDN) to reduce the need for exchange transfusion ${ }^{(2)}$. Immunoglobulins seem to block Fc receptors on macrophages, which reduces the breakdown of antibody coated erythrocytes and lowers the circulating unconjugated bilirubin levels. 
Administration of intravenous immunoglobulin $(0.5-1 \mathrm{gm} / \mathrm{kg})$ is currently recommended by the American Academy of Pediatrics (AAP) if the total serum bilirubin rising despite intensive phototherapy or the bilirubin level is within $2-3 \mathrm{mg} / \mathrm{dl}(34-51$ $\mu \mathrm{mol} / \mathrm{L})$ of the exchange level ${ }^{(3)}$. After the introduction of IVIG, the need for exchange transfusion has reduced. The current recommendations of the American Academy of Pediatrics and the National Advisory Committee on Blood and Blood Products of Canada and Canadian Blood Services advice the use of IVIG for the treatment of haemolytic disease of newborn with established jaundice. IVIG has emerged as an important component of treatment in isoimmune hemolytic jaundice. Recommended dose of IVIG is $0.5-1.0 \mathrm{~g} / \mathrm{kg}$ in neonates with isoimmune hemolytic anemia $^{(4)}$.

The aim of the present study was to assess the efficacy of intravenous immunoglobulins in neonates with $\mathrm{Rh}$ and/or $\mathrm{ABO}$ incompatibility in reducing the duration of phototherapy and the need for exchange transfusion and hospital stay.

\section{Patients and methods}

This clinical intervention study was carried out over one year between 1/11/2016 to 1/11/2017 at Neonatal Intensive Care Unit (NICU) in Pediatrics Department, Tanta University Hospital, in Tanta city. It was approved by the Ethical Committee of the Faculty of Medicine, Tanta University. Written informed consents from all the subjects' fathers were obtained.

A total of 40 neonates with isoimmune haemolytic hyperbilirubinemia were enrolled in our study. All of them suffering from neonatal indirect hyperbilirubinemia (neonatal jaundice) manifested by yellowish discolouration of eyes and skin. Neonates enrolled in this study were divided into 2 groups as follow: Group A: Included 20 neonates who received phototherapy only. Group B: Included 20 neonates who received phototherapy plus intravenous immunoglobulin. The neonate received intravenous immunoglobulin in a single dose of $0.5 \mathrm{gm} / \mathrm{kg}$ of body weight over 4 hours. Both groups received phototherapy under standard conditions with 4 special white 420-480 nanometer lamps. The distance from the light source to the infants was 40 to $50 \mathrm{~cm}$. Neonate with isoimmune haemolytic jaundice proved by ABO or Rh incompitability between blood group of the mother and the baby with significant hyperbilirubinaemia (hyperbilirubinaemia requiring phototherapy and/or rising by 0.5 $\mathrm{mg} / \mathrm{dl}$ per hour) were included in this study. Also neonates with conjugated bilirubin above $2 \mathrm{mg} / \mathrm{dl}$ or exceeding $15 \%$ of total serum bilirubin (TSB), those with congenital anomalies, those with clinical signs of neonatal sepsis, and those with other causes of haemolysis and hyperbilirubinaemia or Neonate with birth injury and asphyxia were excluded.

All neonates in both groups were subjected to: (a) complete history taking (b) Full clinical examination: General physical examination: 1. Assessment of gestational age, weight, length and head circumference. 2. Vital signs including: temperature, respiratory rate and pulse. 3 . General appearance including: activity, skin color and presence of obvious congenital 
anomalies. 4. Skin as regards: jaundice, pallor, plethora, cyanosis and mottling.5. Head as regards: anterior and posterior fontanels and evidence of increased intracranial pressure. 6. Chest as regards: symmetry, breath sounds and signs of respiratory distress. 7. Heart as regards: heart rate, quality of heart sounds and presence of audible murmurs. 8. Abdomen as regards: obvious defects, auscultation for bowel sounds and palpation for distention, tenderness, masses or organomegaly. 9. Genitalia for presence of any abnormalities. 10. Visible jaundice is an indication to check the bilirubin level and should not rely on visual inspection alone to estimate the bilirubin level in a baby with jaundice, either in the serum or via transcutaneous bilirubinometry.

\section{Blood sampling:}

- Blood samples were withdrawn immediately after admission and before starting any treatment from both groups, 5 $\mathrm{ml}$ of venous blood collected on two tubes. The first one contained EDTA as anticoagulant in which $2 \mathrm{ml}$ were collected $(1 \mathrm{ml}$ for complete haemogram and the remaining $1 \mathrm{ml}$ for blood group, $\mathrm{Rh}$ factor typing and Coomb's test). The second tube was plain tube, in which $3 \mathrm{ml}$ were added and allowed for complete clotting in water bath at $37^{\circ} \mathrm{C}$ after clotting; centrifugation at $1500 \times$ for 10 minutes was performed. Serum separated was collected for TSB and CRP then $0.5 \mathrm{ml}$ of blood collected for TSB and DSB every 24 hours tills the end of phototherapy.

- $1 \mathrm{ml}$ of maternal venous blood was collected on a tube contained EDTA as anticoagulant for blood group and $\mathrm{Rh}$ factor typing to be compared with neonatal blood type.

All patients and controls were subjected to the following investigations:

1- Estimation of Serum bilirubin levels (total and direct): it was estimated automatically using a Synchrou Cx9 Pro automated BEckMAn coulter.

2- Determination of coomb 'test: Antiglobulin reagent specific for IgG had been used.

3- Reticulocytic count.

4- Phototherapy: Under standard conditions with 4 special white 420-480 nanometer lamps was used. Complete blood count (CBC): The evaluation was done using counter model (ADVIA 60).

5- Preparation and administration of intravenous immunoglobulin: The neonates of group B only were treated by $0.5 \mathrm{gm} / \mathrm{kg}$ single dose of IV-Globulin S (Heat-treated Immune Serum Globulin) at the time of admission through IV infusion over 4 hour. Estimation of serum bilirubin was done after 4 hours from termination of infusion and then every 24 hours.

6- Exchange transfusion: was given to the patients of both groups when the total serum bilirubin reached $25 \mathrm{mg} / \mathrm{dl}$ or more, or rise by $0.5 \mathrm{mg} / \mathrm{dl}$ per hour under complete aseptic technique.

\section{Statistical analysis:}

In addition to the descriptive data, statistical analysis was done using IBM SPSS STATISTC VERSION 20 PROGRAM. Data were expressed as mean \pm SD and analyzed using the Chi square $\left(\chi^{2}\right)$ test, Fisher's Exact or Monte Carlo correction, Student t-test, Paired t-test, 
ANOVA test, Mann Whitney test and Friedman test to assess the significance of difference in the levels between different parameters. $P<0.05$ was accepted as significant.

\section{RESULTS}

Laboratory assessments of the measured parameters in the different submitted groups are presented in the following tables and figures:

- As regards gender, gestational age and birth weight there was no statistically significant difference between the two studied groups where $\mathrm{p}$ value equals $0.525,0.165$ and 0.073 respectively (table 1).

Table (1): Comparison between the two studied groups according to demographic data

\begin{tabular}{|c|c|c|c|c|c|c|}
\hline & \multicolumn{2}{|c|}{ Group $A(n=20)$} & \multicolumn{2}{|c|}{ Group B $(n=20)$} & \multirow{2}{*}{$\begin{array}{c}\text { Test of } \\
\text { Significan. }\end{array}$} & \multirow[t]{2}{*}{$\mathbf{p}$} \\
\hline & No. & $\%$ & No. & $\%$ & & \\
\hline \multicolumn{7}{|c|}{ Gender } \\
\hline Male & 8 & 40.0 & 10 & 50.0 & \multirow{2}{*}{$\begin{array}{c}\chi^{2}= \\
0.404\end{array}$} & \multirow[b]{2}{*}{0.525} \\
\hline Female & 12 & 60.0 & 10 & 50.0 & & \\
\hline \multicolumn{7}{|c|}{ Gestational age(weeks) } \\
\hline Mean \pm SD. & \multicolumn{2}{|c|}{$38.10 \pm 0.55$} & \multicolumn{2}{|c|}{$37.80 \pm 0.77$} & & \\
\hline Median & \multicolumn{2}{|c|}{38.0} & \multicolumn{2}{|c|}{38.0} & & \\
\hline \multicolumn{7}{|c|}{ Birth weight $(\mathrm{kg})$} \\
\hline Mean \pm SD. & \multicolumn{2}{|c|}{$3.21 \pm 0.39$} & \multicolumn{2}{|c|}{$3.01 \pm 0.27$} & & \\
\hline Median & \multicolumn{2}{|c|}{3.16} & \multicolumn{2}{|c|}{3.10} & & \\
\hline
\end{tabular}

$\chi^{2}, \mathrm{p}: \chi^{2}$ and $\mathrm{p}$ values for Chi square test for comparing between the two groups

$\mathrm{t}, \mathrm{p}$ : $\mathrm{t}$ and $\mathrm{p}$ values for Student t-test for comparing between the two groups

Group A: Receive phototherapy only. Group B: Receive phototherapy plus intravenous.

- There was no statistically significant difference observed between the two studied groups as regards blood group and coomb's test of the infant and blood group of the mother, where $p$ value equals 1.000 for both (table 2).

Table (2): Comparison between the studied groups according to blood group and coomb's test

\begin{tabular}{|c|c|c|c|c|c|c|}
\hline & \multicolumn{2}{|c|}{ Group A $(n=20)$} & \multicolumn{2}{|c|}{ Group B $(n=20)$} & \multirow[t]{2}{*}{$\chi^{2}$} & \multirow[t]{2}{*}{$\mathbf{P}$} \\
\hline & No. & $\%$ & No. & $\%$ & & \\
\hline \multicolumn{7}{|c|}{ Blood group (Mother) } \\
\hline A- & 2 & 10.0 & 2 & 10.0 & \multirow{4}{*}{0.269} & \multirow{4}{*}{$\begin{array}{r}{ }^{\mathrm{MC}} \mathrm{p}= \\
1.000\end{array}$} \\
\hline B- & 3 & 15.0 & 3 & 15.0 & & \\
\hline $\mathrm{O}+$ & 10 & 50.0 & 10 & 50.0 & & \\
\hline $\mathrm{O}-$ & 5 & 25.0 & 5 & 25.0 & & \\
\hline $\mathrm{ABO}$ & 15 & 75.0 & 15 & 75.0 & \multirow[b]{2}{*}{0.0} & \multirow[b]{2}{*}{1.000} \\
\hline RH & 5 & 25.0 & 5 & 25.0 & & \\
\hline \multicolumn{7}{|c|}{ Blood group (infant) } \\
\hline A - & 2 & 10.0 & 1 & 5.0 & \multirow{4}{*}{0.753} & \multirow{4}{*}{1.000} \\
\hline $\mathrm{A}+$ & 8 & 40.0 & 9 & 45.0 & & \\
\hline B - & 1 & 5.0 & 1 & 5.0 & & \\
\hline $\mathrm{B}+$ & 9 & 45.0 & 9 & 45.0 & & \\
\hline \multicolumn{7}{|c|}{ Coomb's test } \\
\hline Negative & 0 & 0.0 & 0 & 0.0 & \multirow[t]{2}{*}{-} & \multirow[t]{2}{*}{-} \\
\hline Positive & 20 & 100.0 & 20 & 100.0 & & \\
\hline
\end{tabular}

$\chi^{2}, \mathrm{p}: \chi^{2}$ and $\mathrm{p}$ values for Chi square test for comparing between the two groups

${ }_{\mathrm{M}} \mathrm{p}$ : $\mathrm{p}$ value for Monte Carlo for Chi square test for comparing between the two groups. 
- As regards comparison between the two studied groups on admission there was no statistically significant difference observed, p value equal 0.130 and 0.868 respectively (table 3 ).

- As regards comparison between reticulocytic count on admission and discharge in group A and group B, there was statistically significant difference observed, p value $<0.001$ for both (table 3).

Table (3): Comparison between the two studied groups according to reticulocytic count (\%) (Retics)

\begin{tabular}{|c|c|c|c|c|}
\hline Retics (\%) & Group A $(n=20)$ & Group B $(\mathbf{n}=20)$ & $\mathbf{t}$ & $\mathbf{p}$ \\
\hline \multicolumn{5}{|l|}{ Admission } \\
\hline Min. - Max. & $4.0-11.80$ & $4.10-16.0$ & \multirow{3}{*}{1.547} & \multirow{3}{*}{0.130} \\
\hline Mean \pm SD. & $6.90 \pm 2.07$ & $8.08 \pm 2.73$ & & \\
\hline Median & 6.55 & 8.10 & & \\
\hline \multicolumn{5}{|l|}{ Discharge } \\
\hline Min. - Max. & $1.80-4.90$ & $1.70-4.40$ & \multirow{3}{*}{0.167} & \multirow{3}{*}{0.868} \\
\hline Mean \pm SD & $3.0 \pm 0.70$ & $2.96 \pm 0.81$ & & \\
\hline Median & 2.90 & 3.0 & & \\
\hline$p_{1}$ & $<0.001^{*}$ & $<0.001^{*}$ & & \\
\hline
\end{tabular}

$\mathrm{t}, \mathrm{p}$ : $\mathrm{t}$ and $\mathrm{p}$ values for Student t-test for comparing between the two groups

$\mathrm{p}_{1}$ : $\mathrm{p}$ value for Paired t-test for comparing between admission and discharge

*: Statistically significant at $\mathrm{p} \leq 0.05$.

- As regards haemoglobin level, haematocrit, red blood cells, platelet count and TLC; there was no statistically significant difference observed with $\mathrm{p}$ values equals $0.111,0.279,0.582$, 0.102 and 0.848 respectively (table 4 ).

Table (4): Comparison between the two studied groups according to CBC

\begin{tabular}{|c|c|c|c|c|}
\hline CBC & Group A $(n=20)$ & Group B $(n=20)$ & Test of Sig. & $\mathbf{P}$ \\
\hline \multicolumn{5}{|c|}{ HB gm/dl } \\
\hline Min. - Max. & $9.80-17.80$ & $12.10-19.30$ & \multirow{3}{*}{$\mathrm{t}=1.630$} & \multirow{3}{*}{0.111} \\
\hline Mean \pm SD. & $14.10 \pm 1.86$ & $15.04 \pm 1.79$ & & \\
\hline Median & 14.35 & 14.45 & & \\
\hline \multicolumn{5}{|l|}{ HCT \% } \\
\hline Min. - Max. & $4.40-55.30$ & $35.10-57.90$ & \multirow{3}{*}{$\mathrm{U}=160.0$} & \multirow{3}{*}{0.279} \\
\hline Mean \pm SD & $40.40 \pm 10.74$ & $44.48 \pm 6.26$ & & \\
\hline Median & 41.70 & 43.15 & & \\
\hline \multicolumn{5}{|c|}{ R.B.C $\left(\times 10^{3}\right) / \mathrm{cmm}$} \\
\hline Min. - Max. & $3.32-5.60$ & $3.60-6.05$ & \multirow{3}{*}{$\mathrm{t}=0.556$} & \multirow{3}{*}{0.582} \\
\hline Mean \pm SD & $4.34 \pm 0.62$ & $4.45 \pm 0.60$ & & \\
\hline Median & 4.35 & 4.47 & & \\
\hline \multicolumn{5}{|c|}{ Platelet $\left(\times 10^{3}\right) / \mathrm{mm3}$} \\
\hline Min. - Max. & $165.0-470.0$ & $150.0-394.0$ & \multirow{3}{*}{$\mathrm{t}=1.677$} & \multirow{3}{*}{0.102} \\
\hline Mean \pm SD. & $293.7 \pm 83.04$ & $253.3 \pm 68.68$ & & \\
\hline Median & 282.50 & 239.50 & & \\
\hline \multicolumn{5}{|c|}{ TLC $\left(\times 10^{3}\right) / \mathrm{mm} 3$} \\
\hline Min. - Max. & $6.30-21.10$ & $6.50-17.30$ & \multirow{3}{*}{$\mathrm{t}=0.193$} & \multirow{3}{*}{0.848} \\
\hline Mean \pm SD. & $11.51 \pm 3.73$ & $11.73 \pm 3.66$ & & \\
\hline Median & 11.35 & 12.10 & & \\
\hline
\end{tabular}

$\mathrm{t}, \mathrm{p}$ : $\mathrm{t}$ and $\mathrm{p}$ values for Student t-test for comparing between the two groups 
$\mathrm{U}, \mathrm{p}$ : U and $\mathrm{p}$ values for Mann Whitney test for comparing between the two groups

Group A: Receive phototherapy only. Group B: Receive phototherapy plus intravenous.

- As regards reduction of total serum bilirubin; there was statistically significant difference observed for comparison between cases with ABO blood group and cases with RH blood group (in group $\mathrm{B}$ only) with $\mathrm{P}$ value equal 0.009. IVIG is more effective in ABO cases than RH cases (table 5).

Table (5): Relation between Blood group (Mother) and Reduction in T.S.B in group B (n= 30)

\begin{tabular}{|c|c|c|c|c|}
\hline & \multicolumn{2}{|c|}{ Blood group (Mother) } & \multirow{2}{*}{$\mathbf{t}$} & \multirow{2}{*}{$\mathbf{p}$} \\
\hline & $\operatorname{ABO}(n=15)$ & RH $(n=5)$ & & \\
\hline \multicolumn{5}{|c|}{ Reduction in T.S.B } \\
\hline Min. - Max. & $4.90-22.0$ & $2.40-8.20$ & \multirow{3}{*}{$2.903^{*}$} & \multirow{3}{*}{$0.009^{*}$} \\
\hline Mean \pm SD. & $12.13 \pm 5.07$ & $5.16 \pm 2.65$ & & \\
\hline Median & 10.80 & 3.90 & & \\
\hline
\end{tabular}

$\mathrm{t}, \mathrm{p}$ : $\mathrm{t}$ and $\mathrm{p}$ values for Student t-test for association between Blood group (Mother) and Change T.S.B

*: Statistically significant at $\mathrm{p} \leq 0.05$.

- As regards comparison between the different studied periods according to decrease of total serum bilirubin in both groups. In group (A) and (B) there was decrease in serum bilirubin in second, third, fourth, and fifth day of admission in comparison with the first day of admission, so there is statistically significant difference observed, p value <0.001(table 6).

- There is statistically significant difference observed between both groups (A) and (B) in decrease of serum bilirubin in second, third, fourth, and fifth day of admission in comparison with the first day of admission, where $\mathrm{p}$ value $<0.05$ (table 6).

Table (6): Comparison between the different studied periods according to decrease of total serum bilirubin in both groups

\begin{tabular}{|c|c|c|c|c|c|c|c|}
\hline \multirow[t]{2}{*}{ T.S.B } & \multicolumn{5}{|c|}{ At Admission } & \multirow{2}{*}{$\mathbf{F}$} & \multirow{2}{*}{$\mathbf{p}$} \\
\hline & 1st day & $2^{\text {nd }}$ day & 3rd day & 4th day & 5th day & & \\
\hline \multicolumn{8}{|l|}{$\begin{array}{c}\text { Group A } \\
(\mathbf{n}=\mathbf{2 0})\end{array}$} \\
\hline Min. - Max. & $7.60-29.50$ & $7.50-25.50$ & $10.10-22.40$ & $9.70-20.10$ & $8.70-19.0$ & \multirow{3}{*}{$23.76^{*}$} & \multirow{3}{*}{$<0.001^{*}$} \\
\hline Mean \pm SD. & $18.17 \pm 5.60$ & $15.68 \pm 4.26$ & $15.37 \pm 3.0$ & $13.73 \pm 2.57$ & $11.98 \pm 2.67$ & & \\
\hline Median & 17.05 & 16.05 & 14.95 & 13.50 & 11.25 & & \\
\hline $\mathbf{p}_{1}$ & & $0.005^{*}$ & 0.094 & 0.001 & $<0.001^{*}$ & & \\
\hline \multicolumn{8}{|l|}{$\begin{array}{l}\text { Group B } \\
(n=20)\end{array}$} \\
\hline Min. - Max. & $10.90-29.0$ & $6.90-21.0$ & $7.70-20.0$ & $7.40-19.10$ & $5.20-15.50$ & \multirow{3}{*}{33.55} & \multirow{3}{*}{$<0.001^{*}$} \\
\hline Mean \pm SD. & $18.32 \pm 5.02$ & $12.86 \pm 3.78$ & $13.05 \pm 3.31$ & $11.54 \pm 3.24$ & $9.52 \pm 2.85$ & & \\
\hline Median & 18.10 & 14.15 & 12.85 & 10.65 & 9.10 & & \\
\hline $\mathbf{p}_{1}$ & & $<0.001$ & $0.003^{*}$ & 0.001 & $<0.001$ & & \\
\hline
\end{tabular}

F p: F and p values for Post Hoc test (Bonferroni) for ANOVA with repeated measures for comparison between different periods $\mathrm{p}_{1}$ : $\mathrm{p}$ value comparison between $1^{\text {st }}$ day and each other periods in each group $\quad *$ : Statistically significant at $\mathrm{p} \leq 0.05$ 

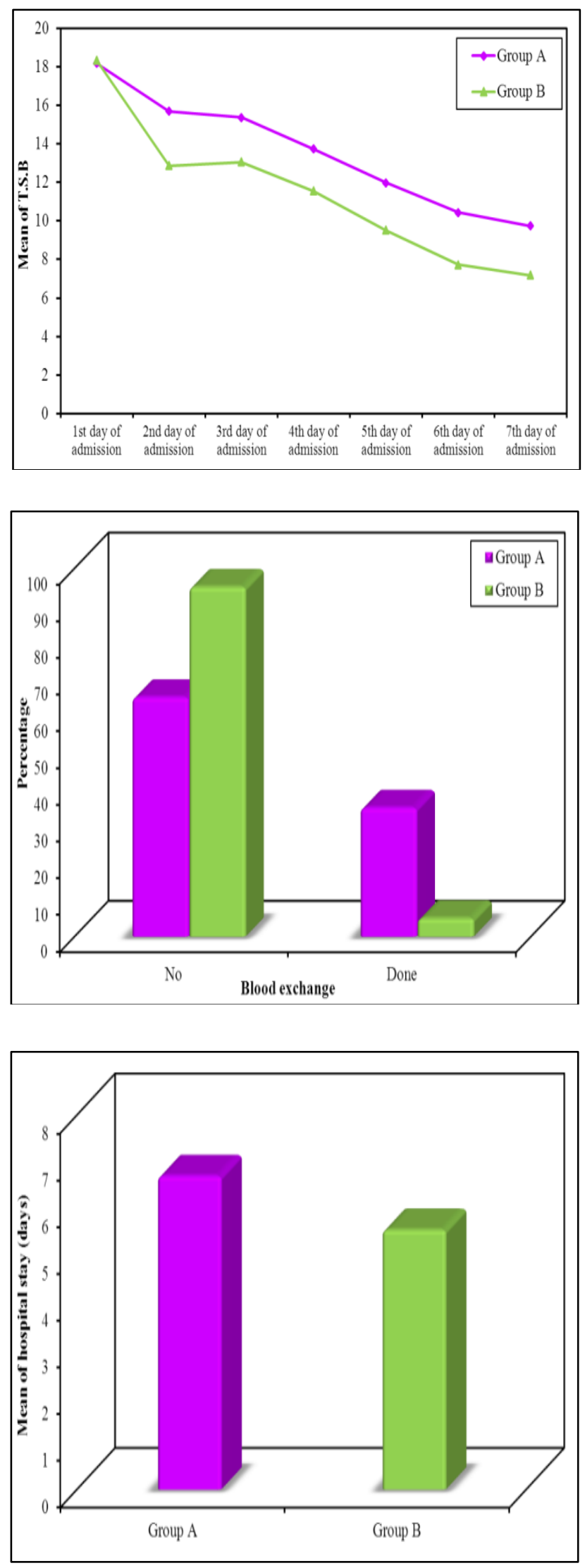

Figure (1): Comparison between the two studied groups according to T.S.B in all days of admission.

- In first day of admission, there was no statistically significant difference observed between the two studied groups.

- In other days of admission, there was statistically significant difference observed between the two studied groups.

Figure (2): Comparison between the two studied groups according to blood exchange.

- There was higher number exchanged blood from group A (7 cases) than those of group B (1 case) from total cases (20 in each group), so there was statistically significant difference observed between the two studied groups.

Figure (3): Comparison between the two studied groups according to Hospital stays (days).

- As regard hospital stay there was statistically significant difference observed between two studied groups. 


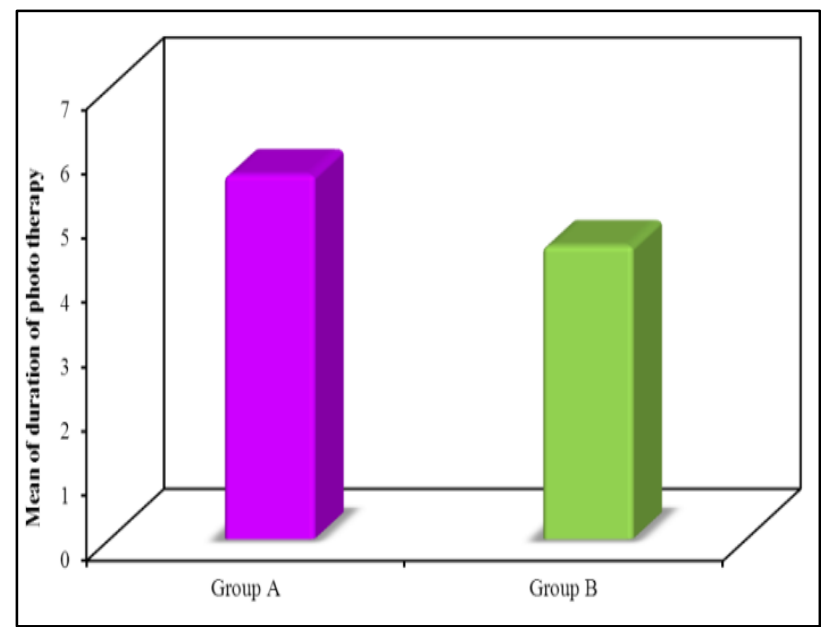

\section{DISCUSSION}

The majority of newborns develop neonatal jaundice, which is the most common cause of hospital admission or rehospitalization in the first week of life Severe unconjugated hyperbilirubinemia is a critical condition which can lead to irreversible brain damage (kernicterus) already in early childhood and eventually can be lethal when left untreated (6) Hemolytic jaundice is the major cause of neonatal jaundice, followed by a lack of proper feeding. ABO incompatibility was the most common cause of hemolytic jaundice $(73.7 \%)$, followed by $\mathrm{Rh}$ disease $(18.7 \%)^{(5)}$.

Neonatal use of IVIG to treat hemolytic anemia was first reported in 1987 by Hara et al. (7) as being successful in the treatment of late anemia due to rhesus $E$ incompatibility. Since that time, numerous reports have been published discussing its use in other forms of haemolytic disease of the newborn, mainly blood group incompatibility, which has proven effective and reduced the need for more invasive treatments such as exchange transfusion.
Figure (4): Comparison between the two studied groups according to duration of phototherapy

- There is statistically significant difference observed between both groups as regards duration of phototherapy (days).

Immunoglobulins seem to block Fc receptors on macrophages, which reduces the breakdown of antibody coated erythrocytes and lowers the circulating unconjugated bilirubin levels. Administration of intravenous immunoglobulin $(0.5-1 \mathrm{gm} / \mathrm{kg})$ is currently recommended by the AAP if the total serum bilirubinis rising despite intensive phototherapy or the bilirubin level is within $2-3 \mathrm{mg} / \mathrm{dL}(34-51 \mu \mathrm{mol} / \mathrm{L})$ of the exchange level (3) The advent of maternal rhesus immunoglobulin prophylaxis, phototherapy, and exchange transfusion reduced the rates of bilirubin-induced mortality and morbidity. However, acute bilirubin encephalopathy and kernicterus are still reported in low- and middle income countries and even high-income countries (5)

Neonates in our study were full term with gestational age ranged from (37 to 39) weeks of gestation, there was no statistically significant difference as regards age. This was in agreement with Khan, ${ }^{(8)}$ who studied 60 full term neonates divided into 
two groups with gestational age ranged from (36 to 39) weeks of gestation, they reported that there was no statistically significant difference between both groups as regards gestational age. El Habashy et al. ${ }^{\text {(9) }}$ did their studies on 116 neonates, (62) of them were full term and (54) of them were preterm distributed between two groups with gestational age ranged from (32 to 39) weeks of gestation, there was no significant difference between both groups as regards gestational age. Also Zwiers et al. ${ }^{\text {(2) }} \mathrm{did}$ their studies on 658 full term and preterm neonates distributed between two groups, this study reported no significant difference as regards gestational age.

In the current study there was no statistically significant difference between group A and group B in the distribution of gender, birth weight, mother group, infant group, and family history. This was in agreement with Beken et al. (10) they reported that a total of 117 babies were studied: 71 babies received IVIG plus phototherapy and 46 received phototherapy only. There was no statistically significant difference in the distribution of gender, mean birth weight, mother's blood group, baby's blood group, and family history among the two groups.

The results of the current study were also in agreement with Zwiers et al. ${ }^{(2)}$ who showed no significant difference as regards weight, and gender. This was in disagreement with Mostafa et al. ${ }^{(11)}$ who studied on 180 full term neonates divided into two groups (group received IVIG and other not received), each one consisted of 90 neonates, they found significant difference between the two groups according to family history, mother blood group, and birth weight.

The present study revealed no significant difference between the two groups (A and $\mathrm{B}$ ) as regarding the hemoglobin level, reticulocytic count and the initial level of serum bilirubin. This was in agreement with Beken et al. (10) who reported no significant difference between the two groups as regarding hemoglobin level, reticulocytic count and the initial level of serum bilirubin. And this was in agreement with Khan, ${ }^{(8)}$ who detected also in their studies no statistical difference as regarding the hemoglobin level, reticulocytic count and the initial level of serum bilirubin between the two groups.

In the present study, the rate of decline in total serum bilirubin after 24 hours was significantly higher among those who received IVIG, where mean \pm SD equaled $12.86 \pm 3.78$, but mean \pm SD in cases with phototherapy only equaled $15.68 \pm 4.26$ after 24 hours. This was in agreement with ElHabashy et al. ${ }^{(9)}$ who reported also more decline in total serum bilirubin in IVIG group with mean \pm SD equaled 12.9 \pm 5.2 , but mean \pm SD in cases with phototherapy only equaled 17.4 \pm 3.3 after 24 hours. The current study used IVIG in group B which consisted of 20 neonates with pathological hyperbilirubinaemia (haemolytic jaundice), 15 of them were ABO (75\%), and 5of them were RH (25\%) with a single dose $500 \mathrm{mg}$ $/ \mathrm{kg}$. This was in agreement with Lieberman et al. ${ }^{\text {(12) }}$ who studied efficacy of IVIG on 37 neonates, 30 of them were $\mathrm{ABO}(81 \%)$, and 7 of them were RH (19\%) with single dose $500 \mathrm{mg} / \mathrm{kg}$. Other dose regimens were tried by El Habashy et al. ${ }^{\text {(9) }}$ who found that low 
dose of IVIG $(500 \mathrm{mg} / \mathrm{kg})$ reduce duration of phototherapy and hospital stay like high dose (1000 mg / kg), but less effective in avoiding exchange transfusion in $\mathrm{Rh}$ hemolytic disease of newborn.

Tanyer et al. ${ }^{(13)}$ also studied the effect of multiple doses $(500 \mathrm{mg} / \mathrm{kg})$ IVIG therapy during 3 consecutive days versus single dose $(500 \mathrm{mg} / \mathrm{kg})$ IVIG therapy on 61 neonates with iso-immmune hemolytic hyperbilirubinemia due to $\mathrm{ABO}, \mathrm{Rh}$ or subgroup incompatibility between mother and baby and below the levels of exchange transfusion criteria. There were three groups; group (I) received multiple dose IVIG treatment, group (II) received single dose IVIG treatment, group (III) was not given any IVIG; and was considered as control group. There was no need for exchange transfusion in group (I); in group (II), exchange transfusion was performed in 3 out of 20 infants (12\%) and in group (III) 7 infants needed exchange transfusion and one of theme also required two exchange transfusions. The rate of exchange transfusion in multiple doses IVIG treatment group, Group (I), was lower than group (II) $(p<0.01)$. Also the rate of exchange transfusion in group (II) was lower than group (III) (control group) $(\mathrm{p}<0.05)$. Gottstein and Cooke (14) Systematically reviewed the effect of intravenous immunoglobulins in hemolytic disease of the newborn, comparing four controlled trials on 226 neonates and all the studies included showed a beneficial effect, despite the variation in IVIG doses. They suggested that a single dose of $500 \mathrm{mg} / \mathrm{kg}$ is as effective as any other dose regimen.

Concerning the need for exchange transfusion the present study found that there was a highly Significant decrease in the number of cases who needed exchange transfusion in the group treated with IVIG (20 patients), where only one of them $(5 \%)$ required exchange transfusion in view of 7 cases $(35 \%)$ of the other group (20 patients) who were in need for exchange transfusion with $\mathrm{p}$ value equals 0.044 . These results were in agreement with Kushwah et al. ${ }^{(4)}$ who studied the effect of a single dose IVIG $(500 \mathrm{mg} / \mathrm{kg})$ on neonates with significant hyperbilirubinemia due to isoimmune hemolytic disease. Zweirs et al. (2) also showed that the rate of exchange transfusion decreased significantly in the immunoglobulin treated group.

The results of the current study were in agreement with Khan ${ }^{(8)}$ who reported that low dose of IVIG decreased the need for exchange transfusion, where only 1 patient of group A needed exchange transfusion (3.4\%) while on the other hand group B patients who were not treated with immunoglobulins needed more exchange transfusion 16 patients $(48.4 \%)$. Also the present study found that low dose of IVIG $(500 \mathrm{mg} / \mathrm{kg}$ ) reduce the duration of phototherapy, where mean $\pm \mathrm{SD}$ in cases with IVIG was $(5.65 \pm 0.93)$ higher than mean \pm SD of the other group $(4.55 \pm 1.15)$ and so, significant difference with $\mathrm{p}$ value (0.003). We found also significant difference between the two studied groups as regards hospital stay, where mean $\pm \mathrm{SD}$ in IVIG group was $(6.70 \pm 0.86)$ higher than mean \pm SD of the other group $(5.55 \pm 1.15)$ with $\mathrm{p}$ value $(0.001)$. This was in agreement with El Habashy et al. ${ }^{(9)}$ who reported that a single high dose of IVIG could be a safe and effective therapy for reducing the need 
for exchange transfusion and duration of phototherapy (where there was significant difference between IVIG group and control group with $\mathrm{p}$ value $<0.001$ ) and hospital stay (there was significant difference between IVIG group and control group with $\mathrm{p}$ value $<0.001$ ) in significant hyperbilirubinemia of $\mathrm{Rh}$ and $\mathrm{ABO}$ hemolytic disease of neonates. The financial saving from shortened inpatient stay and duration of phototherapy offsets the cost of IVIG.

The results of the present study were also in agreement with a prospective study Migdad et al. (15) who randomized 112 term neonates with $\mathrm{ABO}$ hemolytic disease: First group received phototherapy plus IVIG $(0.5 \mathrm{~g} / \mathrm{kg})$ and the second group received phototherapy alone. They concluded that IVIG reduces the need for exchange transfusion in ABO hemolytic disease of the newborn. Other study done by Mundy and Bhatia (7) who gave IVIG with dose (500 $\mathrm{mg} / \mathrm{kg}$ to $1 \mathrm{gm} / \mathrm{kg}$ ), this study found that IVIG decrease the need for exchange transfusion in haemolytic disease of newborn.

Corvaglia et al. ${ }^{\text {(16) }}$ demonstrated that IVIG may decrease the risk of neurological impairment because IVIG decreases time in the high-risk zones on the Bhutani nomogram. The current study was in agreement with Cortey et al. (17) who studied on full term neonates with ABO incompitability, the study was done on two groups one of them received IVIG (.5 to 1 $\mathrm{gm} / \mathrm{kg}$ ) with phototherapy and the other group received phototherapy only, they study found that IVIG decrease the need of exchange transfusion, decrease hospital stay, and duration of phototherapy.
The current study was in disagreement with Beken et al. (10) who found that IVIG don't decrease duration of phototherapy (where $\mathrm{p}$ value between both groups <0.05), nor hospital stay (where $\mathrm{p}$ value between both groups $<0.05$ ), there was no exchange transfusion done to any of the two groups and found that Phototherapy seems to have the key role in these patients. The present study reported that there were no immediate adverse effects related to IVIG including fever, allergic reactions, volume overload or hemolysis, which agreed the findings observed by several studies $(2,7,8,13,18,15$ and 19)

who detected no immediate adverse effects related to IVIG.

\section{Conclusion}

The present study concluded that using IVIG in isoimmune haemolytic jaundice of neonates may be more effective in $\mathrm{ABO}$ cases than RH cases. Also; a single low dose of IVIG $(0.5 \mathrm{gm} / \mathrm{kg})$ is effective in isoimmune haemolytic jaundice, and so will be more economical to patients than other dose regimens. Using combination of intravenous immunoglobulin with phototherapy in full term neonates with indirect hyperbilirubinemia decreased the peak of total serum bilirubin, duration of exposure to phototherapy, duration of hospital stay, and decrease the need for exchange transfusion.

\section{REFERENCES}

1- Özcan M, Sevinç S, Erkan V et al. (2017): Hyperbilirubinemia due to minor blood group (anti-E) incompatibility in a newborn: a case report. Turkish Archives of Pediatrics/Türk Pediatri Arşivi., 52(3): 162164.

2- Zwiers C, Scheffer-Rath M, Lopriore E $e t$ al. (2018): Immunoglobulin for alloimmune 
hemolytic disease in neonates. DOI: 10.1002/14651858.CD003313.pub2.

3- Ree I, Smits-Wintjens V, van der B et al. (2017): Neonatal management and outcome in alloimmune hemolytic disease. Expert review of hematology, 10(7): 607-616.

4- Kushwah S, Kumar A, George $\mathbf{N}$ et al. (2017): A case of coombs-positive severe late anemia without hyperbilirubinemia, refractory to blood transfusion, improved with immunoglobulin. CHRISMED Journal of Health and Research, 4(3): 212-213.

5- Erdeve O, Okulu E, Olukman O et al. (2018): The Turkish Neonatal Jaundice Online Registry: A national root cause analysis. PloS one, 13(2): e0193108.

6- Van Dijk R, Aronson S, Dirk $\mathrm{R}$ et al. (2017): Biliverdin Reductase inhibitors did not improve severe unconjugated hyperbilirubinemia in vivo. Scientific reports, 7(1): 1646- 1649.

7- Mundy C , Bhatia J (2015): Immunoglobulin transfusion in hemolytic disease of the newborn: place in therapy. International Journal of Clinical Transfusion Medicine, 3: 41-45.

8- Khan S (2013): Effect of Intravenous Immunoglobulin in Reducing Bilirubin Levels in Hemolytic Disease of Newborn. Journal of Rawalpindi Medical College, 17(2): 172-174.

9- El Habashy S, Toaima D, Gad G et al. (2014). High dose intravenous immunoglobulin in $\mathrm{Rh}$ and $\mathrm{ABO}$ hemolytic disease of Egyptian neonates. Egyptian Journal of Pediatric Allergy and Immunology , 12(1), 21-26.

10- Beken S, Hirfanoglu I, Turkyilmaz C et al. (2014): Intravenous immunoglobulin $G$ treatment in $\mathrm{ABO}$ hemolytic disease of the newborn, is it myth or real?. Indian Journal of Hematology and Blood Transfusion, 30(1): 12-15.
11- Mostafa S, Aljeesh Y, Hamad K et al. (2017) Risk Factors of Hyperbilirubinemia among Admitted Neonates in the Gaza Strip: Case Control Study. Public Health Research, 7(2): 39-45.

12- Lieberman L, Spradbrow J, Keir A et al. (2016): Use of intravenous immunoglobulin in neonates at a tertiary academic hospital: a retrospective 11-year study. Transfusion, 56(11): 2704-2711.

13- Tanyer G, Siklar Z, Dallar Y et al. (2001): Brief report. Multiple dose IVIG treatment in neonatal immune hemolytic jaundice. Journal of tropical pediatrics, 47(1): 50-53.

14- Gottstein R , Cooke R (2003): Systematic review of intravenous immunoglobulin in haemolytic disease of the newborn. Archives of Disease in Childhood-Fetal and Neonatal Edition, 88(1): F6-F10.

15- Miqdad A, Abdelbasit O, Shaheed M et al. (2004): Intravenous immunoglobulin $G$ (IVIG) therapy for significant hyperbilirubinemia in $\mathrm{ABO}$ hemolytic disease of the newborn. The Journal of Maternal-Fetal \& Neonatal Medicine, 16(3): 163-166.

16- Corvaglia L, Legnani E, Galletti $S$ et al. (2012): Intravenous immunoglobulin to treat neonatal alloimmune haemolytic disease. The Journal of Maternal-Fetal \& Neonatal Medicine, 25(12): 2782-2785.

17- Cortey A, Elzaabi M, Waegemans T et al. (2014): Efficacy and safety of intravenous immunoglobulins in the management of neonatal hyperbilirubinemia due to $\mathrm{ABO}$ incompatibility: a meta-analysis. Archives de Pediatrie, 21(9): 976-83.

18- Alpay F, Sarici S, Okutan V et al. (1999): High-dose intravenous immunoglobulin therapy in neonatal immune haemolytic jaundice. Acta Paediatrica, 88(2): 216-219.

19- Mukhopadhyay K, Murki S, Narang A et al. (2003): Intravenous immunoglobulins in rhesus hemolytic disease. The Indian Journal of Pediatrics, 70(9): 697-699. 